\title{
The Effects of Climate Therapy on Cardiorespiratory Fitness and Exercise-Induced Bronchoconstriction in Children with Asthma
}

\author{
Carlo De Pieri ${ }^{1, * \mathbb{D}}$, Michele Arigliani ${ }^{1} \mathbb{D}^{\mathbb{D}}$, Maria Pia Francescato ${ }^{2} \mathbb{D}$, Maurizio Droli $^{3} \mathbb{D}$, Michael Vidoni $^{1}$, \\ Ilaria Liguoro ${ }^{1} \mathbb{D}$, Maria Elena Ferrari ${ }^{1}$, Paola Cogo $^{1}$ and Mario Canciano Canciani ${ }^{1}$
}

1 Department Medicine, Division of Pediatrics, University Hospital of Udine, 33100 Udine, Italy; michelearigliani@gmail.com (M.A.); vidoni.ts@gmail.com (M.V.); ilarialiguoro@gmail.com (I.L.); mary6ferrari@gmail.com (M.E.F.); paola.cogo@uniud.it (P.C.); mccanciani@gmail.com (M.C.C.)

2 Department of Medicine, University of Udine, 33100 Udine, Italy; mariapia.francescato@uniud.it

3 Department of Agricultural, Food, Environmental and Animal Science, Section of Economics, University of Udine, 33100 Udine, Italy; maurizio.droli@uniud.it

* Correspondence: carlodepieri@gmail.com

Citation: De Pieri, C.; Arigliani, M.; Francescato, M.P.; Droli, M.; Vidoni, M.; Liguoro, I.; Ferrari, M.E.; Cogo, P.; Canciani, M.C. The Effects of Climate Therapy on Cardiorespiratory Fitness and Exercise-Induced

Bronchoconstriction in Children with Asthma. Atmosphere 2021, 12, 1486. https://doi.org/10.3390/atmos12111486

Academic Editors: Samuel

Yutong Cai and Andrés

Alastuey Urós

Received: 17 October 2021

Accepted: 8 November 2021

Published: 10 November 2021

Publisher's Note: MDPI stays neutral with regard to jurisdictional claims in published maps and institutional affiliations.

Copyright: (c) 2021 by the authors. Licensee MDPI, Basel, Switzerland. This article is an open access article distributed under the terms and conditions of the Creative Commons Attribution (CC BY) license (https:/ / creativecommons.org/licenses/by/ $4.0 /)$.

\begin{abstract}
We investigated whether a 1-week stay in the mountains may have a positive impact on Exercise-Induced Bronchoconstriction (EIB) and cardiorespiratory endurance in asthmatic children from an urban area. Spirometry was performed before and $10 \mathrm{~min}$ after a $20 \mathrm{~m}$ shuttle run test (20mSRT) on the first and seventh day of a summer asthma camp in the Italian Alps at $900 \mathrm{~m}$ of altitude. Spirometry z-scores were derived from the Global Lung Initiative 2012 prediction equations, and percentiles of the 20mSRT performance were assigned according to De Miguel-Etayo's and Tomkinson's predictive equations. $\mathrm{A} \mathrm{FEV}_{1}$ decrease $\geq 10 \%$ after the exercise was defined as EIB. Particulate matter pollution was monitored during the camp and in the urban area of provenience. Twenty-four subjects (age range 7-16 years) were included. Frequency of EIB decreased from 58\% $(14 / 24)$ at day-1 to $33 \%(8 / 24)$ at the end of the camp $(p=0.08)$. Most subjects with a $20 \mathrm{mSRT}$ in the lowest quartile at day 1 had EIB (9/11). The proportion of children with a $20 \mathrm{mSRT}<25^{\circ}$ percentile decreased from $45 \%(11 / 24)$ at day-1 to $16 \%(4 / 24)$ at day-7 $(p=0.02)$. Conclusion: One-week climate therapy in the mountains improved both bronchial hyperreactivity and cardiorespiratory endurance in our cohort of asthmatic children.
\end{abstract}

Keywords: pediatric asthma; exercise-induced bronchoconstriction; $20 \mathrm{~m}$ shuttle run test

\section{Introduction}

There is conflicting evidence regarding the benefits of climate therapy in the mountains for children with asthma [1-6], whereas higher evidence of effectiveness is available for adults with refractory asthma [1]. Allergen sensitization, airway eosinophilia, type 2 inflammation and outdoor air pollution are recognized triggers of asthma at school-age [7]. On the other hand, dry climate and low levels of allergens and pollution, together with high UV exposure, may contribute to improving airway inflammation and asthma symptoms in a mountain setting [8].

In particular, in asthmatic children sensitized to house dust mites (HDM), allergen avoidance in the context of climate therapy in the mountains may improve bronchial hyperresponsiveness and exercise tolerance [9], decrease serum total IgE and specific IgE to HDM [9], and also lead to a reduction of airway eosinophilic inflammation markers [9,10].

Whether asthma has an impact on aerobic fitness or not is also controversial [11-14]. Some authors reported a reduced cardiorespiratory endurance (CRE) in asthmatic children $[11,15,16]$, which seems to depend more on inadequate levels of exercise $[17,18]$ or poor self-perception of physical capability [19] rather than on Exercise-Induced Bronchoconstriction (EIB). In fact, cardiorespiratory fitness in these patients tends to normalize with a proper training, while EIB does not $[20,21]$. Some degree of EIB is present in most patients 
with allergic asthma [22], and its magnitude correlates with the degree of airway hyperresponsiveness and airways eosinophilic inflammation [23,24]. The presence of EIB can be assessed through an exercise challenge test, and a positive response is generally considered a decrease of at least $10 \%$ of the baseline $\mathrm{FEV}_{1}$ after the challenge [25]. In asthmatic children, a positive exercise challenge test (i.e., $10 \% \mathrm{FEV}_{1}$ reduction) is associated with a poor control of asthma symptoms [26]. The pathophysiology of EIB in subjects with asthma depends on an increase in osmolarity of the airways surface liquid triggered by inhalation of large volumes of dry air during exercise $[27,28]$, which in turn causes the release of inflammatory mediators such as histamine, cysteinyl leukotrienes and prostaglandins [29]. Such inflammatory response, which occurs also in non-asthmatic subjects during exercise, in the context of asthma-related chronic airway inflammation can easily trigger symptomatic bronchospasm [22].

In this study, we hypothesized that an asthma camp in the mountains in children with variable degrees of asthma severity could result in an improvement of airway inflammation and frequency of EIB. We also hypothesized that improved asthma control would result in a better CRE at the end of the camp. More specifically, we evaluated changes in EIB and CRE from baseline to the end of a 1-week asthma camp in the Italian Alps in a cohort of urban school-aged children with asthma [30].

\section{Materials and Methods}

The study population was children and adolescents with asthma from an urban area (Udine, in north-east Italy), who attended a summer asthma camp. The camp consisted in a one-week stay in a mountain village in the Italian Alps (Fusine lakes, Tarvisio, FriuliVenezia Giulia region) at $900 \mathrm{~m}$ of altitude above the sea level. During the camp, the participants practiced daily outdoor physical activity and received training about selfmanagement of asthma. The presence of experienced educators at the camp guaranteed compliance to therapy of the participants. The study was granted ethics approval. Parental written consent and verbal assent from each subject were obtained.

At baseline, parents answered the GINA 2015 assessment of asthma control questionnaire, where the following questions were asked regarding asthma symptoms in the previous 4 weeks: (a) "Daytime symptoms more than twice a week?", (b) "Any night waking due to asthma?", (c) "Short-acting beta-2 agonist reliever needed more than twice a week?", (d) "Any activity limitation due to asthma?"; asthma is then classified as "well controlled" if answer is "NO" to all the questions, "partly controlled" if there are 1-2 "YES" answers and "uncontrolled" if there are 3-4 "YES" answers [31]. Each subject performed a spirometry test just before (T0) and 10 min after (T10') a $20 \mathrm{~m}$ shuttle run test (20mSRT) on days 1 and 7 (last day) of the camp. A portable spirometer (Spirolab, MIR, Rome, Italy), meeting the European Respiratory Society/American Thoracic Society (ERS/ATS) requirements, was used [32]. At each data point, children performed from two to seven forced expiratory maneuvers, standing upright with nares occluded by a nose clip. Tests were included if there were at least two forced expiratory maneuvers meeting the ERS/ATS acceptability and repeatability criteria for spirometry, adapted for children $[33,34]$. Spirometry quality control was performed by two investigators expert in spirometry (CDP and MA) using the same overread method. Participants performed only one post-exercise spirometry at $\mathrm{T} 10^{\prime}$. This strategy was adopted considering that the nadir in $\mathrm{FEV}_{1}$ usually occurs within 5-10 min from exercise cessation [25] and that staff was insufficient to perform more tests. Exercise induced bronchoconstriction was defined as a $\mathrm{FEV}_{1}$ volume decrease of $\geq 10 \%$ after the $20 \mathrm{mSRT}$ [25]. The $20 \mathrm{mSRT}$ (also known as Léger test) is a validated and widely used tool to assess CRE in children and adolescents [35-39]. It consists of an incremental test where the subject runs back and forth between two lines $20 \mathrm{~m}$ apart, while pacing is dictated from pre-recorded audio signals. The frequency of the sound signals increases in such a way that running speed increases by $0.5 \mathrm{~km} / \mathrm{h}$ each minute from a starting speed of $8.5 \mathrm{~km} / \mathrm{h}$. The test stops when the subject is no longer able to follow the set pace [37]. The FVC, $\mathrm{FEV}_{1}$ and $\mathrm{FEV}_{1} / \mathrm{FVC}$ were expressed as 
z-scores according to the Global Lung Initiative 2012 (GLI-2012) prediction equations [40]. Percentiles of 20mSRT performances were assigned according to De Miguel-Etayo's reference values for children aged 7-9 years and to Tomkinson's for older subjects [41,42]. Differences between groups and differences in test results at the beginning and at the end of the asthma camp were compared using unpaired $t$ test and one-tailed Fisher's exact test as appropriate. The $95 \% \mathrm{CI}$ around difference of means is presented for $\mathrm{t}$ test results. A $p$-value $<0.05$ was considered a statistically significant difference. Statistical analyses were performed using GraphPad Prism version 7.04 (La Jolla, CA 92037, USA).

Air quality monitoring in the urban area of provenience (Udine, Italy) is provided by the Regional Environment Protection Agency, which owns a network of monitoring stations. Real-time and historical data of PM2.5, PM10, NOX, CO, Ozone and other pollutants are available. At the asthma-camp site, aerosol mass concentration (MC) was tracked by adopting a battery-operated DustTrak II/DRX (TSI Inc., US-IL, Shoreview, MN, USA) aerosol particulate device. Two real-time single-channeled light-scattering laser photometer sampling periods were established every day during the stay from 8 to 13 am and from 2 to $7 \mathrm{pm}$. Thus, the total sampling length period was $10 \mathrm{~h}$ per day, corresponding to a $70 \mathrm{~h}$ total sampling period.

\section{Results}

A total of 40 subjects were initially enrolled. All participants completed the 20mSRT. Sixteen patients were excluded because they had incomplete spirometry data (e.g., refusal to perform spirometry at one of the data points) or poor-quality spirometry at one of the data points. Twenty-four participants ( 14 boys and 10 girls, mean \pm SD age $11.8 \pm 2.0$ years, age range 7.4-16.3) were included in the final analysis. Seventeen out of $24(71 \%)$ patients had well-controlled asthma, 6/24 (25\%) partially controlled, and 1/24 (4\%) uncontrolled asthma according to the GINA 2015 assessment of asthma control questionnaire [31]. One third of the participants $8 / 24$ (33\%) had non-allergic asthma. Spirometry and 20mSRT results at baseline and at the end of the asthma camp are summarized in Table 1.

Table 1. Spirometry and $20 \mathrm{~m}$ shuttle run test results of asthmatic children participating in a summer camp at moderate altitude $(900 \mathrm{~m})$.

\begin{tabular}{cccc}
\hline & Asthma Camp Day 1 & Asthma Camp Day 7 & $\begin{array}{c}\text { Difference between Means } \\
\text { Day 7 and Day 1 (95\% CI) }\end{array}$ \\
\hline N. Subjects (boys/girls) & $24(14 / 10)$ & $0.11(-0.45 ; 0.65)$ \\
\hline zFEV1 pre-exercise & $0.10(0.95)$ & $0.21(0.96)$ & $0.40(-0.15 ; 0.95)$ \\
\hline zFVC pre-exercise & $0.09(0.96)$ & $0.49(0.94)$ & $-0.48(-1.05 ; 0.06)$ \\
\hline zFEV1/FVC pre-exercise & $-0.02(1.01)$ & $-0.50(0.84)$ & $p$ \\
\hline Frequency of EIB & $14(58 \%)$ & $8(33 \%)$ & 0.08 \\
\hline $\begin{array}{l}\text { Frequency of } 20 \mathrm{mSRT} \\
\text { performance }<25^{\circ} \text { pc }\end{array}$ & $11(45 \%)$ & $4(16 \%)$ & 0.02 \\
\hline
\end{tabular}

Definition of abbreviations: $\mathrm{zFEV1}$ = z-score for FEV1; zFVC = z-score for FVC; zFEV1/FVC = z-score for FEV1/FVC; EIB = exercise-induced bronchoconstriction; 20mSRT $=20 \mathrm{~m}$ shuttle run test. Results are presented as mean (SD) unless otherwise specified. Spirometry z-scores based on Global Lung channeled light-scattering [28]; 20mSRT performance percentile based on De Miguel-Etayo's for children aged $7-9$ years and on Tomkinson's for older subjects $[29,30]$.

Average pre-exercise FVC of asthmatic subjects increased by $0.4 \mathrm{z}$-scores $(95 \% \mathrm{CI}$, $-0.15 ; 0.95)$ throughout the camp, while $\mathrm{FEV}_{1}$ had only a slight increment of $0.11 \mathrm{z}$-scores $(95 \%$ CI $-0.45 ; 0.65)$ (Table 1). The frequency of EIB in this cohort dropped from $58 \%$ $(14 / 24)$ at the beginning of the stay in the mountains to $33 \%(8 / 24)$ on the last day $(p=0.08)$ (Table 1).

Eleven out of $24(45 \%)$ asthmatic children had a 20mSRT performance $<25^{\circ}$ percentile on the first day of the camp and, among them, 9/11 showed EIB. After 7 days in moun- 
tain environment, the proportion of subjects with a 20mSRT performance in the lowest quartile dropped to $17 \%(4 / 24)(p=0.02)$. Sixteen out of 24 patients $(66 \%)$ improved their performance at the $20 \mathrm{mSRT}$ from the beginning to the end of the camp (Figure 1).

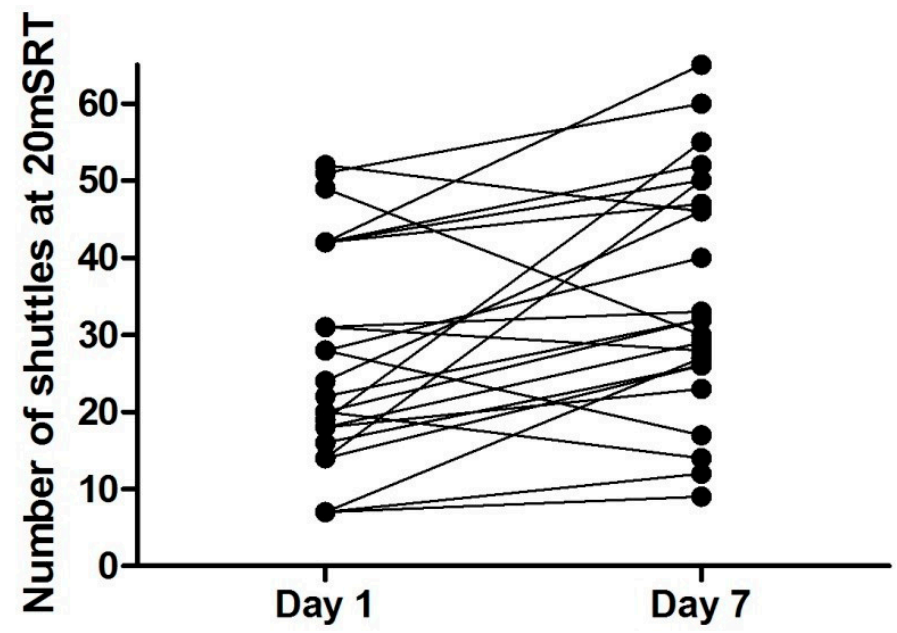

Figure 1. Number of shuttles performed at the $20 \mathrm{~m}$ shuttle run test (20mSRT) by each subject (black dot) on the first (Day 1) and last day (Day 7) of a summer asthma camp at low altitude (900 m) in the Italian Alps. Mean number of shuttles performed was $26.6 \pm 14.6$ at day 1 and $33.7 \pm 14.9$ at day 7 $(p<0.001)$.

At the asthma camp site, the average MC for PM2.5 resulted as $3.75(+1.75 /-1.25) \mu \mathrm{g} / \mathrm{m}^{3}$ and for PM10, $5.5(+18 /-1.75) \mu \mathrm{g} / \mathrm{m}^{3}$. In the urban area, in the same period, the average PM2.5 and PM10 MC resulted as $9.80(+8.20 /-5.40) \mu \mathrm{g} / \mathrm{m}^{3}$ and $14.20(+10.00 /-6.00) \mu \mathrm{g} / \mathrm{m}^{3}$, respectively.

\section{Discussion}

In this study, the proportion of asthmatic children that had exercise-induced bronchoconstriction and poor cardiorespiratory fitness improved after a one-week stay in the mountains at non-high altitude $(<1500 \mathrm{~m})$.

A systematic review, including randomized controlled trials and single-armed studies evaluating the effects of climate therapy at $1500-2500 \mathrm{~m}$ on $\mathrm{FEV}_{1}$ performance or bronchial hyper-reactivity in asthmatic patients [3], revealed the lack of sufficient evidence to recommend this approach, though most of the analyzed studies showed positive results. More recently, a meta-analysis of studies performed at altitude higher than $1500 \mathrm{~m}$, including a total 907 children and adults with asthma, pointed out a meaningful clinical improvement in $\mathrm{FEV}_{1}, \mathrm{FEV}_{1} / \mathrm{FVC}$ ratio or peak expiratory flow rate after climate therapy in 13 out of 28 studies evaluated [6]. In our study, a 1-week climate therapy at low altitude in the mountains mainly improved the FVC of the asthmatic children; the changes in the average $\mathrm{FEV}_{1}$ and FVC $\mathrm{z}$-scores from the beginning to the end of the camp, however, were not statistically significant, probably also because of a limited sample size. In a mountain environment, the lower burden of allergens and outdoor air pollution as well as better sunlight exposure and lower air density than in an urban environment may improve chronic airway inflammation [43]. Christie et al., for example, showed that asthmatic children temporarily residing in the mountains at moderate altitude had an increase in urinary leukotriene E4 levels (marker of eosinophilic airway inflammation) after a stay at sea level [4]. Boner and colleagues showed in several studies that a summer asthma camp in the alps in children with allergic asthma to HDM improved bronchial hyper-responsiveness, exercise tolerance and markers of eosinophilic airway inflammation [9,10,44,45].

In this study, we could not assess airway inflammation markers, but the frequency of EIB in our cohort of asthmatic patients almost halved following the asthma camp (from $58 \%$ to $33 \%$ ) and, although statistical significance was not reached $(p=0.08)$ (likely because 
of the small sample size), we still think that such a change in EIB strongly suggests a beneficial effect on airway inflammation due to the climate therapy. A potential confounder of this finding would be a better compliance to asthma preventive therapy (e.g., inhaled corticosteroids) due supervised drug administration during the asthma camp. We could not measure adherence to asthma therapy before the one-week stay in the mountains, and therefore, we are not able to rule out this confounder. However, since this was a cohort of young patients with chronic asthma well known to our service, with no social concerns and very well supported by families educated on asthma care, it would be surprising if there were changes in adherence to asthma therapy during the asthma camp. Finally, alternative mechanisms such as psychological or emotional factors derived from a better familiarity of participants with spirometry technique at the end of the asthma camp are not likely to have affected our findings because: (a) participants have regular follow-up in an asthma clinic that includes periodical spirometry tests, and therefore, they were already experienced in performing spirometry at the time of the intervention; (b) a strict quality control of all spirometry tests included at each data point was carried out that, indeed, led to eliminate a number of subjects $(16 / 40,40 \%)$ who had poor quality tests at one or more data points or incomplete spirometry data (e.g., refusal to perform spirometry at one of the data points).

The stay in the mountains also had a beneficial effect on the cardiorespiratory fitness of the participants, considering that the proportion of subjects with a poor 20mSRT performance (lowest quartile of the reference population) dropped from $45 \%(11 / 24)$ at the beginning of the camp to $24 \%(4 / 24)$ at the end of it $(p=0.02)$. A reduced level of aerobic fitness in an asthmatic pediatric population was previously reported [12,15]. Many factors seem to influence athletic performance in asthmatic patients, the most important being the level of habitual physical activity [10], the severity of airflow limitation $[19,46]$ and some psychological issues, such as the level of self-perceived competence in exercise [19]. In our study, participants performed regular physical activity throughout the asthma camp, and most of them improved bronchial hyper-reactivity during the stay in the mountains. These factors could justify an improvement in cardiorespiratory fitness and 20mSRT performance. However, it is possible that at the end of the asthma camp, participants were more self-confident about competence in exercise, and certainly, they were more familiar with the $20 \mathrm{mSRT}$ test which, differently, from spirometry, is not routinely performed in the follow-up of this group. These factors, namely self-confidence and familiarity with 20mSRT, are difficult to quantify, but might have confounded our findings of overall improved 20mSRT performance results at the end of asthma camp in our cohort of asthmatic children. Unfortunately, we could not think of any strategy or analysis that would adequately adjust for these potential confounders.

Less exposure to outdoor air pollution is likely to have an important role in determining the beneficial effects of climate therapy: Renzetti et al. showed a remarkable increase of the peak expiratory flow and a significant reduction in airway inflammatory biomarker levels, such as nasal eosinophils and fractional exhaled nitric oxide, in a group of asthmatic children who were relocated for one week from highly polluted urban environment to a less polluted mountain environment [47]. Our findings are consistent with that study, showing that a short stay in the mountains improved bronchial hyperresponsiveness in asthmatic children coming from an urban environment, where they were exposed to higher outdoor pollution, as shown by higher levels of PM2.5 and PM10 measured simultaneously in the city of provenience (Udine, Italy) and in the mountain setting (Fusine lakes, Tarvisio, Italian Julian Alps) during the asthma camp.

The beneficial effect of climate therapy for asthmatic patients has been mainly attributed to the low presence of allergens at moderate and high altitude, in particular for people sensitized to HDM. However, both allergic and non-allergic asthma patients seem to benefit from this approach, as it was recently demonstrated in a Dutch study [8]. In our study, we found an improvement in the frequency of EIB among asthmatic patients, although the climate therapy was performed at a non-elevated altitude $(900 \mathrm{~m})$ where the distribution of allergens should not be dramatically different from lower altitudes [48]. 
Therefore, other specific factors, such as a low air pollution, high UV exposure (which leads to increased vitamin D levels), increased physical activity and possibly improved adherence to medical therapy, may have played a role even more important than the low allergens presence in improving airway inflammation during the stays in the mountains $[47,49,50]$.

This study has a number of limitations. At the asthma-camp site, due to the lack of any permanent monitoring station, aerosol mass concentration was tracked by adopting a battery-operated device raising a possible bias to different sampling techniques. Permanent stations monitoring for PM use relatively expensive equipment and allow the collection of highly detailed data. Nevertheless, despite this advantage, those stations often limit the spatial distribution of ambient PM data available [51]. On the other hand, the use of more portable and affordable PM monitors has recently been suggested as a means through which to integrate data gathered by permanent station networks [52]. The study sample was limited, and a control group was missing. Levels of allergens at the asthmacamp site were not assessed, and therefore, it is impossible to establish at which extent a reduced exposure to allergens contributed to the findings in the asthma cohort. Direct airway inflammation markers were not measured, but we used EIB as a surrogate of airway inflammation as the presence of EIB indicates poor asthma control and should reflect worse airway inflammation, at least in allergic asthma [22]. A control group would have been particularly useful in particular for the interpretation of changes in 20mSRT performance, which is more subject to confounding than changes in EIB. Unfortunately, it was not possible to arrange a control group due to logistic problems but also for ethics reasons, as children without asthma would not have any reason to take part in an asthma camp. We have already commented in the discussion regarding how a better familiarity of participants with the $20 \mathrm{mSRT}$ at the end of asthma camp could have contributed to the overall improved performance [37]. Furthermore, children with asthma often experience psychological distress due to their condition [53], and the relationship with their peers could improve their engagement in the experiment, together with better adherence to therapy due to supervised medication administration. Finally, the time of intervention was only one week, and it could be argued that this is a too-small interval to appreciate clinically meaningfully changes in a chronic condition like asthma, though our data do not point to this direction. Moreover, there was not a follow-up assessment to evaluate how long the positive effects of climate therapy on bronchial hyper-responsiveness and cardio-respiratory fitness lasted.

The study also presents some strengths. All the tests were performed by the same investigators, using the same equipment and methodology. The use of the most updated reference values for spirometry and for 20mSRT performances allowed a more precise classification of the results. Adequate physical activity during the camp and compliance to therapy of the participants were guaranteed by the presence of experienced educators. Finally, air quality was strictly monitored at the asthma-camp site by an experienced investigator (MD) who stayed at the camp for the entire monitoring period.

\section{Conclusions}

In conclusion, this pilot study showed a positive effect of climate therapy in a mountain setting on bronchial hyper-responsiveness and cardio-respiratory fitness of asthmatic children living in an urban area. Low-pollution, daily physical activity, optimal compliance to therapy and, probably, lower levels of allergens at the asthma-camp site may have contributed to these results. However, these findings need to be confirmed on adequately powered controlled cohorts, and the pathophysiology mechanisms of the apparent beneficial effect of climate therapy on aerobic fitness in asthmatic patients needs to be better clarified.

Author Contributions: C.D.P. and M.A. conceptualized the study; collected, reviewed and analyzed data; and drafted and revised the manuscript. M.V., M.P.F., M.D., M.E.F. and I.L. collected data and drafted the manuscript. P.C. and M.C.C. conceptualized and supervised the study and revised the manuscript. All authors have read and agreed to the published version of the manuscript. 
Funding: The non-profit patient group "Associazione ALPI" financially supported the publication of the study.

Institutional Review Board Statement: All procedures performed in studies involving human participants were in accordance with the ethical standards of the institutional and/or national research committee and with the 1964 Helsinki declaration and its later amendments or comparable ethical standards.

Informed Consent Statement: Informed consent was obtained from all individual participants included in the study.

Conflicts of Interest: The authors declare no conflict of interest.

\section{References}

1. Rijssenbeek-Nouwens, L.H.; Bel, E.H. High-altitude treatment: A therapeutic option for patients with severe, refractory asthma? Clin. Exp. Allergy 2011, 41, 775-782. [CrossRef]

2. Warner, J.O. Asthma, allergen avoidance and residence at high altitude. Pediatric Allergy Immunol. 2009, 20, 509. [CrossRef]

3. Massimo, T.; Blank, C.; Strasser, B.; Schobersberger, W. Does climate therapy at moderate altitudes improve pulmonary function in asthma patients? A systematic review. Sleep Breath. 2014, 18, 195-206. [CrossRef] [PubMed]

4. Christie, P.E.; Yntema, J.L.; Tagari, P.; Ysselstijn, H.; Ford-Hutchinson, A.W.; Lee, T.H. Effect of altitude on urinary leukotriene (LT) E4 excretion and airway responsiveness to histamine in children with atopic asthma. Eur. Respir. J. 1995, 8, 357-363. [CrossRef] [PubMed]

5. Straub, D.A.; Ehmann, R.; Hall, G.L.; Moeller, A.; Hamacher, J.; Frey, U.; Sennhauser, F.H.; Wildhaber, J.H. Correlation of nitrites in breath condensates and lung function in asthmatic children. Pediatric Allergy Immunol. 2004, 15, 20-25. [CrossRef] [PubMed]

6. Vinnikov, D.; Khafagy, A.; Blanc, P.D.; Brimkulov, N.; Steinmaus, C. High-altitude alpine therapy and lung function in asthma: Systematic review and meta-analysis. ERJ Open Res. 2016, 2, 00097-2015. [CrossRef]

7. Saglani, S.; Fleming, L.; Sonnappa, S.; Bush, A. Advances in the aetiology, management, and prevention of acute asthma attacks in children. Lancet Child Adolesc. Health 2019, 3, 354-364. [CrossRef]

8. Bersuch, E.; Gräf, F.; Renner, E.D.; Jung, A.; Traidl-Hoffmann, C.; Lauener, R.; Roduit, C. Lung function improvement and airways inflammation reduction in asthmatic children after a rehabilitation program at moderate altitude. Pediatric Allergy Immunol. 2017, 28, 768-775. [CrossRef]

9. Peroni, D.G.; Boner, A.L.; Vallone, G.; Antolini, I.; Warner, J.O. Effective allergen avoidance at high altitude reduces allergeninduced bronchial hyperresponsiveness. Am. J. Respir. Crit. Care Med. 1994, 149, 1442-1446. [CrossRef]

10. Piacentini, G.L.; Peroni, D.G.; Bodini, A.; Boner, A.L. Exhaled nitric oxide in children with asthma at high altitude. J. Allergy Clin. Immunol. 2007, 120, 1226-1227. [CrossRef]

11. McNarry, M.A.; Boddy, L.M.; Stratton, G.S. The relationship between body mass index, aerobic performance and asthma in a pre-pubertal, population-level cohort. Eur. J. Appl. Physiol. 2014, 114, 243-249. [CrossRef]

12. Strunk, R.C.; Rubin, D.; Kelly, L.; Sherman, B.; Fukuhara, J. Determination of fitness in children with asthma. Use of standardized tests for functional endurance, body fat composition, flexibility, and abdominal strength. Am. J. Dis. Child. 1988, 142, 940-944. [CrossRef] [PubMed]

13. Ahmaidi, S.B.; Varray, A.L.; Savy-Pacaux, A.M.; Prefaut, C.G. Cardiorespiratory fitness evaluation by the shuttle test in asthmatic subjects during aerobic training. Chest 1993, 103, 1135-1141. [CrossRef] [PubMed]

14. Santuz, P.; Baraldi, E.; Filippone, M.; Zacchello, F. Exercise performance in children with asthma: Is it different from that of healthy controls? Eur. Respir. J. 1997, 10, 1254-1260. [CrossRef]

15. Wong, T.W.; Yu, T.S.; Wang, X.R.; Robinson, P. Predicted maximal oxygen uptake in normal Hong Kong Chinese schoolchildren and those with respiratory diseases. Pediatric Pulmonol. 2001, 31, 126-132. [CrossRef]

16. Lochte, L. Predicted aerobic capacity of asthmatic children: A research study from clinical origin. Pulm. Med. 2012, $2012,854652$. [CrossRef]

17. Fink, G.; Kaye, C.; Blau, H.; Spitzer, S.A. Assessment of exercise capacity in asthmatic children with various degrees of activity. Pediatric Pulmonol. 1993, 15, 41-43. [CrossRef]

18. Lang, D.M.; Butz, A.M.; Duggan, A.K.; Serwint, J.R. Physical activity in urban school-aged children with asthma. Pediatrics 2004, 113, e341-e346. [CrossRef] [PubMed]

19. Pianosi, P.T.; Davis, H.S. Determinants of physical fitness in children with asthma. Pediatrics 2004, 113, e225-e229. [CrossRef] [PubMed]

20. Neder, J.A.; Nery, L.E.; Silva, A.C.; Cabral, A.L.; Fernandes, A.L. Short-term effects of aerobic training in the clinical management of moderate to severe asthma in children. Thorax 1999, 54, 202-206. [CrossRef]

21. Thio, B.J.; Nagelkerke, A.F.; Ketel, A.G.; van Keeken, B.L.; Dankert-Roelse, J.E. Exercise-induced asthma and cardiovascular fitness in asthmatic children. Thorax 1996, 51, 207-209. [CrossRef] [PubMed] 
22. Weiler, J.M.; Bonini, S.; Coifman, R.; Craig, T.; Delgado, L.; Capão-Filipe, M.; Passali, D.; Randolph, C.; Storms, W. American Academy of Allergy, Asthma \& Immunology Work Group report: Exercise-induced asthma. J. Allergy Clin. Immunol. 2007, 119, 1349-1358. [CrossRef] [PubMed]

23. Anderton, R.C.; Cuff, M.T.; Frith, P.A.; Cockcroft, D.W.; Morse, J.L.; Jones, N.L.; Hargreave, F.E. Bronchial responsiveness to inhaled histamine and exercise. J. Allergy Clin. Immunol. 1979, 63, 315-320. [CrossRef]

24. Duong, M.; Subbarao, P.; Adelroth, E.; Obminski, G.; Strinich, T.; Inman, M.; Pedersen, S.; O’Byrne, P.M. Sputum eosinophils and the response of exercise-induced bronchoconstriction to corticosteroid in asthma. Chest 2008, 133, 404-411. [CrossRef]

25. Crapo, R.O.; Casaburi, R.; Coates, A.L.; Enright, P.L.; Hankinson, J.L.; Irvin, C.G.; MacIntyre, N.R.; McKay, R.T.; Wanger, J.S.; Anderson, S.D.; et al. Guidelines for methacholine and exercise challenge testing-1999. This official statement of the American Thoracic Society was adopted by the ATS Board of Directors, July 1999. Am. J. Respir. Crit. Care Med. 2000, 161, 309-329. [CrossRef]

26. Chinellato, I.; Piazza, M.; Sandri, M.; Cardinale, F.; Peroni, D.G.; Boner, A.L.; Piacentini, G.L. Evaluation of association between exercise-induced bronchoconstriction and childhood asthma control test questionnaire scores in children. Pediatric Pulmonol. 2012, 47, 226-232. [CrossRef]

27. Jayasinghe, H.; Kopsaftis, Z.; Carson, K. Asthma Bronchiale and Exercise-Induced Bronchoconstriction. Respir. Int. Rev. Thorac. Dis. 2015, 89, 505-512. [CrossRef] [PubMed]

28. Park, H.K.; Jung, J.W.; Cho, S.H.; Min, K.U.; Kang, H.R. What makes a difference in exercise-induced bronchoconstriction: An 8 year retrospective analysis. PLoS ONE 2014, 9, e87155. [CrossRef]

29. Boulet, L.P.; O’Byrne, P.M. Asthma and exercise-induced bronchoconstriction in athletes. N. Engl. J. Med. 2015, 372, 641-648. [CrossRef]

30. Jung, A.; Heinrichs, I.; Geidel, C.; Lauener, R. Inpatient paediatric rehabilitation in chronic respiratory disorders. Paediatr. Respir Rev. 2012, 13, 123-129. [CrossRef]

31. Global Initiative for Asthma (GINA). Global Strategy for Asthma Management and Prevention. 2018, p. 17, box 12.12. Available online: https: / / ginasthma.org/ (accessed on 7 November 2021).

32. Miller, M.R.; Hankinson, J.; Brusasco, V.; Burgos, F.; Casaburi, R.; Coates, A.; Crapo, R.; Enright, P.; van der Grinten, C.P.; Gustafsson, P.; et al. Standardisation of spirometry. Eur. Respir. J. 2005, 26, 319-338. [CrossRef] [PubMed]

33. Kirkby, J.; Welsh, L.; Lum, S.; Fawke, J.; Rowell, V.; Thomas, S.; Marlow, N.; Stocks, J. The EPICure study: Comparison of pediatric spirometry in community and laboratory settings. Pediatric Pulmonol. 2008, 43, 1233-1241. [CrossRef] [PubMed]

34. Graham, B.L.; Steenbruggen, I.; Miller, M.R.; Barjaktarevic, I.Z.; Cooper, B.G.; Hall, G.L.; Hallstrand, T.S.; Kaminsky, D.A.; McCarthy, K.; McCormack, M.C.; et al. Standardization of Spirometry 2019 Update. An Official American Thoracic Society and European Respiratory Society Technical Statement. Am. J. Respir. Crit. Care Med. 2019, 200, e70-e88. [CrossRef]

35. Tomkinson, G.R.; Léger, L.A.; Olds, T.S.; Cazorla, G. Secular trends in the performance of children and adolescents (1980-2000): An analysis of 55 studies of the 20m shuttle run test in 11 countries. Sports Med. 2003, 33, 285-300. [CrossRef] [PubMed]

36. Hamlin, M.J.; Fraser, M.; Lizamore, C.A.; Draper, N.; Shearman, J.P.; Kimber, N.E. Measurement of cardiorespiratory fitness in children from two commonly used field tests after accounting for body fatness and maturity. J. Hum. Kinet. 2014, 40, 83-92. [CrossRef]

37. Léger, L.A.; Mercier, D.; Gadoury, C.; Lambert, J. The multistage 20 metre shuttle run test for aerobic fitness. J. Sports Sci. 1988, 6, 93-101. [CrossRef] [PubMed]

38. Liu, N.Y.; Plowman, S.A.; Looney, M.A. The reliability and validity of the 20-meter shuttle test in American students 12 to 15 years old. Res. Q. Exerc. Sport 1992, 63, 360-365. [CrossRef]

39. van Mechelen, W.; Hlobil, H.; Kemper, H.C. Validation of two running tests as estimates of maximal aerobic power in children. Eur. J. Appl. Physiol. Occup. Physiol. 1986, 55, 503-506. [CrossRef] [PubMed]

40. Quanjer, P.H.; Stanojevic, S.; Cole, T.J.; Baur, X.; Hall, G.L.; Culver, B.H.; Enright, P.L.; Hankinson, J.L.; Ip, M.S.; Zheng, J.; et al. Multi-ethnic reference values for spirometry for the 3-95-yr age range: The global lung function 2012 equations. Eur. Respir. J. 2012, 40, 1324-1343. [CrossRef]

41. De Miguel-Etayo, P.; Gracia-Marco, L.; Ortega, F.B.; Intemann, T.; Foraita, R.; Lissner, L.; Oja, L.; Barba, G.; Michels, N.; Tornaritis, M.; et al. Physical fitness reference standards in European children: The IDEFICS study. Int. J. Obes. 2014, 38 (Suppl. 2), S57-S66. [CrossRef] [PubMed]

42. Tomkinson, G.R.; Lang, J.J.; Tremblay, M.S.; Dale, M.; LeBlanc, A.G.; Belanger, K.; Ortega, F.B.; Léger, L. International normative $20 \mathrm{~m}$ shuttle run values from 1142026 children and youth representing 50 countries. Br. J. Sports Med. 2017, 51, $1545-1554$. [CrossRef]

43. Sutherland, E.R.; Goleva, E.; Jackson, L.P.; Stevens, A.D.; Leung, D.Y. Vitamin D levels, lung function, and steroid response in adult asthma. Am. J. Respir. Crit. Care Med. 2010, 181, 699-704. [CrossRef] [PubMed]

44. Peroni, D.G.; Piacentini, G.L.; Vicentini, L.; Costella, S.; Pietrobelli, A.; Boner, A.L. Effective allergen avoidance reduces residual volume and sputum eosinophils in children with asthma. J. Allergy Clin. Immunol. 2001, 108, 308. [CrossRef] [PubMed]

45. Bodini, A.; Peroni, D.; Vicentini, L.; Loiacono, A.; Baraldi, E.; Ghiro, L.; Corradi, M.; Alinovi, R.; Boner, A.L.; Piacentini, G.L. Exhaled breath condensate eicosanoids and sputum eosinophils in asthmatic children: A pilot study. Pediatric Allergy Immunol. 2004, 15, 26-31. [CrossRef] [PubMed] 
46. Babb, T.G.; Viggiano, R.; Hurley, B.; Staats, B.; Rodarte, J.R. Effect of mild-to-moderate airflow limitation on exercise capacity. J. Appl. Physiol. 1991, 70, 223-230. [CrossRef] [PubMed]

47. Renzetti, G.; Silvestre, G.; D’Amario, C.; Bottini, E.; Gloria-Bottini, F.; Bottini, N.; Auais, A.; Perez, M.K.; Piedimonte, G. Less air pollution leads to rapid reduction of airway inflammation and improved airway function in asthmatic children. Pediatrics 2009, 123, 1051-1058. [CrossRef]

48. Hashimoto, S.; Bel, E.H. Current treatment of severe asthma. Clin. Exp. Allergy 2012, 42, 693-705. [CrossRef]

49. Mendes, F.A.; Almeida, F.M.; Cukier, A.; Stelmach, R.; Jacob-Filho, W.; Martins, M.A.; Carvalho, C.R. Effects of aerobic training on airway inflammation in asthmatic patients. Med. Sci. Sports Exerc. 2011, 43, 197-203. [CrossRef]

50. Mokhallati, N.; Guilbert, T.W. Moving towards precision care for childhood asthma. Curr. Opin. Pediatrics 2016, 28, 331-338. [CrossRef]

51. Wang, Y.; Li, J.; Jing, H.; Zhang, Q.; Jiang, J.; Biswas, P. Laboratory evaluation and calibration of three low-cost particle sensors for particulate matter measurement. Aerosol Sci. Technol. 2015, 49, 1063-1077. [CrossRef]

52. Holstius, D.M.; Pillarisetti, A.; Smith, K.R.; Seto, E. Field calibrations of a low-cost aerosol sensor at a regulatory monitoring site in California. Atmos. Meas. Tech. 2014, 7, 1121-1131. [CrossRef]

53. Bitsko, M.J.; Everhart, R.S.; Rubin, B.K. The adolescent with asthma. Paediatr. Respir. Rev. 2014, 15, 146-153. [CrossRef] [PubMed] 